\title{
O IMPACTO DAS POLÍTICAS ESTRATÉGICAS DE COMÉRCIO EXTERIOR NO MERCADO INTERNACIONAL DE PRODUTOS AGRÍCOLAS ${ }^{1}$
}

\author{
Regina Célia de Carvalho ${ }^{2}$ \\ Ricardo Chaves Lima ${ }^{3}$
}

Resumo - O mercado internacional de algumas commodities agrícolas é, em geral, caracterizado pela existência de uma estrutura oligopolizada, cujos participantes se comportam de forma não-cooperativa, gerando uma constante disputa por frações de mercado. Neste cenário, a utilização de políticas estratégicas de comércio exterior é aplicada, como instrumento, na disputa por frações de mercado entre os participantes. Nesta abordagem, quando um país adota determinada política estratégica, os efeitos causados sobre as exportações ou importações são imediatamente percebidos pelos demais participantes do mercado. A introdução de subsídios pelos governos de países produtores resulta em elevação do volume exportado, enquanto a cobrança de impostos de importação leva à redução dos volumes negociados no mercado internacional.

Palavras-chave : política estratégica de comércio exterior, comércio internacional.

\section{Introdução}

O mercado internacional de algumas commodities agrícolas, geralmente, é composto por reduzido grupo de produtores ou exportadores e por um grupo de países que tem tradição no consumo deste bem.

\footnotetext{
${ }^{1}$ Este trabalho é baseado na Tese de Doutorado da primeira autora.

${ }^{2}$ Professora da Universidade Federal do Mato Grosso. E-mail: arva3@ig.com.br

${ }^{3}$ Professor da Universidade Federal de Pernambuco. E-mail: rlima@ufpe.br
} 
O número reduzido de participantes neste mercado caracteriza a existência de uma estrutura oligopolizada, que se comporta de forma não-cooperativa, gerando uma constante disputa por frações de mercado.

Nesta disputa, vantagens comparativas e custos de produção são levados em consideração, e outros fatores são utilizados para incentivar ou auxiliar a participação e o domínio dos países na obtenção de parcelas do mercado. Esses fatores são conhecidos como instrumentos de política comercial, que é feita sem um acordo prévio com os demais participantes do mercado, por estes atuarem de forma não-cooperativa.

Esses instrumentos de política estratégica de comércio exterior é o foco central deste trabalho, cujo exame permitirá a compreensão da dinâmica do funcionamento do mercado internacional e a identificação de um melhor posicionamento.

Este estudo objetivou examinar os impactos de políticas estratégicas no mercado internacional de commodities agrícolas, em um ambiente caracterizado por um comportamento não-cooperativo dos oligopólios, e permitirá reunir elementos que possam subsidiar a elaboração de políticas estratégicas a serem aplicadas pelo governo brasileiro no referido mercado.

O desenvolvimento e a abordagem deste assunto serão feitos nos tópicos que seguem e pode ser assim resumidos: (I) Abordagem do comércio internacional voltada para produtos agrícolas; (II) Contextualização do Brasil neste mercado; (III) Modelo teórico utilizado para analisar a utilização de instrumentos de política agrícola; (IV) Análise dos impactos das políticas estratégicas de comércio exterior; e (V) Algumas considerações finais sobre a análise. 


\section{Políticas de comércio exterior}

O século XX foi caracterizado por intensas transformações no cenário mundial, sendo a primeira metade marcada pelas duas Grandes Guerras Mundiais. Outros fatores que merecem destaque, neste período, foram a estruturação e o desenvolvimento das relações comerciais entre as nações.

Dadas as disputas comerciais existentes, foram feitas discussões que culminaram com a assinatura de um Acordo Geral sobre Tarifas Aduaneiras e Comércio (General Agreement on Tariff and Trade GATT) em 1947, assinado por 23 países, inclusive pelo Brasil (WTO, 2003).

Três princípios básicos identificados no GATT e que deveriam ser seguidos por todos os países são a reciprocidade, a não-discriminação e o descrito como "acordos preferenciais", que permitiam a criação de áreas de livre comércio e estavam respaldados pelo Artigo XXIV, do GATT (Bagwell; Staiger, 1997)

Existiam ainda diversas lacunas neste acordo, o que era observado pela falta de consenso nas negociações, ou em temas sobre alguns setores que foram adiados para negociações futuras. Dadas as suas especificidades, o setor que mereceu mais destaque dentro desta categoria foi o agropecuário.

Com o intuito declarado de garantir a segurança alimentar e proteger os interesses dos produtores domésticos, países europeus investiam em políticas de cotas de importação, incentivos fiscais e subsídios. Como exemplo deste sistema de proteção, pode-se citar a Política Agrícola Comum (PAC), criada pela Comunidade Econômica Européia (CEE), o que resultou em confronto de interesses entre os EUA e a CEE. Este conflito, entre outros, geraram intensas negociações que resultaram na separação dos temas relacionados com agricultura da agenda dos acordos relacionados com comércio internacional (Pont-Vieira, 1994). 
Os resultados destas políticas de proteção sempre foram o incentivo ao aumento da produção doméstica e, conseqüentemente, a elevação dos estoques nacionais que são ofertados no mercado internacional, a preços competitivos.

Algumas modificações no cenário do comércio mundial foram observadas no início da década de 70, entre elas, podem-se relacionar: (I) quebra da safra americana; (II) desvalorização do dólar; e (III) crise do petróleo. Esses fatores influenciaram o aumento da participação dos demais países produtores de produtos agrícolas no mercado mundial (Rosário, 2001).

Esse crescimento na participação dos demais países provocou elevação da oferta de produtos e aumento na competitividade entre os participantes, resultando na queda persistente nas cotações dos preços internacionais das principais commodities no mercado internacional. Como forma alternativa de superar essa baixa nos preços, buscou-se incentivar a comercialização de produtos processados, já que estes apresentavam maiores valores agregados, o que aumentava a receita dos países exportadores.

Isto foi particularmente importante para alguns produtos, como, por exemplo, a soja, já que a implementação de indústrias de esmagamento e processamento agrega mais valor ao produto, comercializando o farelo e o óleo, ao invés da soja em grãos (Rosário, 2001).

Com vistas em valorizar o setor de transformação doméstico e respaldar a competitividade no mercado internacional, muitos países utilizam instrumentos estratégicos nas negociações no comércio externo, entre eles, impostos, subsídios à exportação, quotas e restrição voluntária à exportação.

Tanto as pressões domésticas quanto o interesse dos países pela importação de produtos subsidiados colaboram para a adoção de políticas de intervenção nos mercados, além de dificultarem o estabelecimento dos acordos de isenção total de subsídios por parte dos países exportadores (Bagwell; Staiger, 2000). 
Em 1995, as diversas negociações culminaram na criação da Organização Mundial do Comércio (World Trade Organization - WTO), que visa definir regras únicas para solucionar as disputas existentes (WTO, 2003).

No atual sistema tarifário há um escalonamento progressivo para tarifas cobradas na comercialização no produto, determinado com base no grau de processamento do produto. As tarifas cobradas tenderão a zero quando o produto for comercializado in natura, fato que pode ser comprovado nos dados apresentados pelo Ministério do Desenvolvimento, da Indústria e do Comércio (MDIC), em que, em um cenário atual, a União Européia e o Japão isentam da cobrança de tarifas a comercialização da soja em grãos. Segundo dados do MDIC (2003), importações de óleo de soja bruto da União Européia são taxadas com alíquotas de 3,8 a 7,6\% e de óleo refinado, de 6,1 a $11,4 \%$, enquanto no Japão cobram-se 20,7 ienes por quilograma do óleo de soja.

A estrutura do mercado internacional das principais commodities agrícola apresenta características concretas de um sistema oligopolizado, no qual os países participantes se comportam de forma não-cooperativa, o que foi descrito por Brander (1995), Krishna e Thursby (1991) e Carmichael (1987) como jogo de dois estágios. No primeiro momento, os governos decidem a respeito dos instrumentos de política a serem utilizados; em seguida, as firmas tomam suas decisões sobre os investimentos na produção.

A dificuldade na definição de acordos comuns que norteiam as políticas agrícolas leva à implementação de Estratégias para as Políticas de Comércio Exterior, como forma de manutenção das frações de mercados já alcançadas. 


\section{Brasil no contexto mundial}

No ranking do Fundo Monetário Internacional apresentado pelo MDIC (2003), o Brasil foi classificado como o $24^{\circ}$ colocado em Exportações de Mercadorias, no ano de 2000.

A contribuição do setor agropecuário para a economia brasileira é incontestável, já que, de 1991 a 2001, a participação direta deste setor no PIB brasileiro foi, em média, de 8,2\%, sem contar com sua participação indireta por meio do fornecimento de insumos para o setor de manufaturados (MDIC, 2003).

A participação média do agronegócio no montante total das exportações brasileiras foi de 41,57\%, no período de 1990 a 2004. Esses dados refletem a importância desde setor para a economia brasileira, uma vez que o saldo da balança comercial deste setor contribuiu para a determinação do superávit do saldo brasileiro a partir de 2001 (Mapa, 2006).

Esse desempenho da agricultura é resultado de investimentos efetuados no período, que compreende as décadas de 70 a 90 , e, dentre os instrumentos utilizados, destaca-se a Política de Garantia dos Preços Mínimos (PGPM), conforme descrito por Goldin e Rezende (1993) e Rezende (2001).

O sistema de crédito para o setor agropecuário, nas décadas de 70 e 80 , era livre da cobrança de correção monetária, o que caracterizava subsídio ao crédito e favorecia o desenvolvimento do setor (Alves; Araújo, 2002).

Outras variáveis que influenciaram o desempenho da agricultura, em face da realidade da economia brasileira, foram as taxas de juros e a variação nas taxas de câmbio. Segundo Timmer, Falcon e Pearson (1983), o nível das taxas de juros determina as alocações de capital em investimentos produtivos, com fortes implicações no sistema de crédito. 
A taxa cambial influi na remuneração dos produtos exportáveis, já que a comercialização desses produtos é feita com cotações de preços do mercado internacional. As taxas cambiais também afetam as importações de matérias-primas para produção de fertilizantes. Assim, há relação direta entre as taxas de câmbio e os preços dos produtos e dos insumos agrícolas.

De acordo com Figueiredo, Ferreira e Teixeira (1999), os choques ocasionados por desvalorizações cambiais sobre as principais commodities, sem considerar alterações nas políticas tarifárias, e concluíram uma forte influência desta variável sobre o comportamento, tanto da produção como do mercado de insumos. É de consenso, na literatura, que a desvalorização cambial proporciona maior rentabilidade ao seu grau de competência.

O mais recente instrumento de política agrícola utilizado no Brasil e que pode incentivar ainda mais a produção agrícola nacional foi instituído pelo Decreto $n^{\circ} 4.257$, de 04/06/2002 - é a operação chamada de drawback, já utilizada em outros setores, a qual permite a isenção ou suspensão dos pagamentos de tributos na importação de matérias-primas e de outros insumos utilizados no cultivo de produtos agrícolas a serem exportados (Tavares, 2003).

Dadas as dificuldades nas transações comerciais, a utilização de estratégias na determinação das políticas de comércio exterior para o Brasil é o meio mais viável para valorizar a comercialização agrícola brasileira neste mercado. Dessa forma, é importante analisar as políticas estratégicas de comércio exterior destinadas ao setor agropecuário brasileiro e implementadas no setor de exportação. 


\section{Modelo teórico}

A estrutura de competitividade do mercado internacional representa a interrelação existente entre os participantes e os instrumentos de política de comércio exterior, implementados pelos governos envolvidos. Nesse contexto, é necessário avaliar o impacto dessas políticas nos agentes econômicos.

Quando o número de participantes no mercado for reduzido, o poder de mercado de cada participante será maior e haverá possibilidade de os agentes econômicos influenciarem os preços. Essa estrutura de mercado foi definida, por Mas-Collel, Whinston e Green (1995), como oligopólio. Segundo esses autores, a competição entre firmas é determinada por interações estratégicas, e o instrumento adequado para sua análise é a Teoria dos Jogos.

A disputa verificada entre os participantes de um mercado com características oligopolísticas ocorre, basicamente, de duas formas: (i) pela competição por preços (Modelo de Bertrand), ou (ii) pela competição para determinar a quantidade de produto comercializada por cada participante (Modelo de Cournot).

O enfoque principal deste trabalho centra-se no Modelo de Cournot, no qual as firmas, simultaneamente, decidem o quanto produzir e o quanto exportar. Neste modelo, a escolha da produção é determinada de forma estratégica e independente da opção do concorrente, o que caracteriza uma situação de jogo não-cooperativo (Bagwell; Staiger, 2000).

Como a competição caracterizada se dá de forma não-cooperativa, essa concorrência gera uma situação caracterizada como o Dilema do Prisioneiro, vivido por governos dos países participantes, dado o jogo de impostos e subsídios formado na disputa por frações deste mercado (ANIS; ROSS, 1992). O Dilema do Prisioneiro refere-se à situação de solução do problema enfrentado pelos participantes de um jogo, que, por não conhecerem a postura a ser adotada pelos demais participantes, irão optar por situações que ofereçam menores riscos ou perdas. 
Segundo Mas-Collel, Whinston e Green (1995), o equilíbrio de Nash é definido pela melhor resposta estrategicamente escolhida por um jogador para confrontar as estratégias adotadas por seus rivais ou por seus concorrentes. Equilíbrio ou eficiência de Pareto é uma alocação na qual não existe nenhuma outra alocação, tal que, ao melhorar a condição de pelo menos um indivíduo, os demais não tenham perdas.

De acordo com o modelo proposto, quando um país adotar determinada política estratégica, os efeitos causados sobre as exportações serão imediatamente percebidos pelos demais participantes do mercado.

Na busca da maximização do bem-estar nacional, os países levam em consideração o excedente dos consumidores domésticos, o lucro das firmas domésticas, a receita que os governos obtêm de taxas cobradas com a movimentação de produtos estrangeiros, os gastos com subsídios e outros instrumentos de política estratégica utilizados (Anis; Ross, 1992; e Dixit e Grossman, 1986).

As principais suposições do presente modelo são de que: (i) os produtos comercializados serão considerados idênticos; (ii) não haverá consumo nos países produtores; (iii) os governos conhecerão as estruturas das firmas produtoras e serão capazes de determinar políticas de subsídios confiáveis.

Os instrumentos que serão utilizados pelos países são definidos numa etapa anterior à decisão de produção das firmas, que buscam favorecer a opção escolhida pelos agentes econômicos envolvidos (Brander; Spencer, 1984).

Com vistas em simplificar a análise, serão considerados apenas dois países produtores que exportam toda sua produção para um terceiro país (consumidor). Assim, será considerado um país doméstico que compete, neste terceiro mercado, com um país estrangeiro.

Segundo Brander e Spencer (1985) e De Meza (1986), das funções de lucro das firmas exportadoras (doméstica e estrangeira) e das funções 
de bem-estar doméstico dos três países envolvidos, abaixo relacionadas, podem-se obter as quantidades ótimas negociadas por cada país, segundo o tipo de instrumento de política estratégica de comércio exterior utilizado.

$$
\begin{aligned}
& \pi(x, y ; s)=x p(x+y)-c(x)+s x, \\
& \pi^{*}(x, y ; s)=y p(x+y)-c^{*}(y),
\end{aligned}
$$

em que $\pi$ é o lucro da firma doméstica, $x$, produção da firma doméstica, $y$, produção da firma estrangeira, $s$, subsídio unitário do país doméstico, $p(x+y)$, preço do bem; e $c$, custo variável no país doméstico.

As variáveis referentes ao país ou às firmas competidoras serão diferenciadas por asteriscos (*), assim, $\pi^{*}$ é o lucro da firma estrangeira e $c^{*}$, custo variável no país estrangeiro. Define-se também $s$ * como o subsídio unitário do país estrangeiro.

$$
\begin{aligned}
& W(s)=\pi(x, y ; s)-s x, \\
& W^{*}\left(s, s^{*}\right)=\pi^{*}\left(x, y ; s^{*}\right)-s^{*} y, \\
& W^{3}\left(s, s^{*}, t\right)=U(X)-q(X) X+t X,
\end{aligned}
$$

em que $(W)$ é a função de bem-estar doméstico; $\left(W^{*}\right)$, função de bemestar estrangeira; $\left(W^{3}\right)$, função de bem-estar da nação importadora estrangeira; $X$, soma das exportações dos dois outros países $(x+y)$; e $q(X)$, preço pago pelo produto no país consumidor.

Esse preço é diferente do recebido pelas firmas exportadoras, dada a possibilidade da existência de cobrança, pelo país importador, de um imposto ou subsídio fornecido pelo governo. A relação existente entre os dois preços pode ser assim representada: $p(X ; t) \equiv q(X)-t$. 
Os dados das análises de Brander e Spencer (1985), sobre as quantidades ótimas negociadas por cada país e sobre os níveis ótimos de utilização de cada um dos instrumentos de política estratégica de comércio exterior, foram sumarizados na Tabela 1.

Nesta Tabela são apresentados dados da análise da quantidade ofertada pelo país doméstico, considerando a existência: i) de subsídio interno, $x_{s}$; ii) de subsídio externo, $x_{s^{*}}$; e iii) da cobrança de impostos pelo importador $x_{t}$. Essas mesmas análises foram realizadas para verificar o comportamento da quantidade ofertada pelo país estrangeiro, ou seja, $y_{s}, y_{s^{*}}$ e $y_{t}$. Obtidos esses dados, considerou-se $D$ como a condição de Routh-Hurwitz para estabilidade da função de reação ${ }^{1}$. Foram também determinados os níveis ótimos dos instrumentos de políticas estratégicas de comércio exterior, caso sejam utilizados.

Tabela 1 - Quantidades ótimas negociadas por cada país, segundo o tipo de instrumento de política estratégica de comércio exterior (PECE) utilizado

\begin{tabular}{llll}
\hline & Subsídio Doméstico & Subsídio Estrangeiro & Imposto de Importação \\
\hline $\begin{array}{l}\text { Quantidade ofertada } \\
\text { pelo país doméstico }\end{array}$ & $x_{s} \equiv \frac{d x}{d s}=-\frac{\pi_{y y}^{*}}{D}>0$ & $x_{s}{ }^{*} \equiv \frac{d x}{d s^{*}}=\frac{\pi_{x y}}{D}<0$ & $x_{t} \equiv \frac{d x}{d t}=\frac{\left(\pi_{y y}^{*}-\pi_{x y}\right)}{D}$ \\
\hline $\begin{array}{l}\text { Quantidade ofertada } \\
\text { pelo país estrangeiro }\end{array}$ & $y_{s} \equiv \frac{d y}{d s}=\frac{\pi_{y x}^{*}}{D}<0$ & $y_{s^{*}} \equiv \frac{d y}{d s^{*}}=-\frac{\pi_{x x}}{D}>0$ & $y_{t} \equiv \frac{d y}{d t}=\frac{\left(\pi_{x x}-\pi_{y x}^{*}\right)}{D}$ \\
\hline $\begin{array}{l}\text { Nível ótimo do } \\
\text { instrumento de PECE } \\
\text { utilizado }\end{array} \quad \frac{x p^{\prime} y_{s}}{x_{s}}>0$ & $s^{*}=\frac{y p^{\prime} x_{s^{*}}}{y_{s^{*}}}>0$ & $t=-\frac{X\left(1-q^{\prime}(X) X_{t}\right)}{X_{t}}$ \\
\hline
\end{tabular}

Fonte: Brander e Spencer (1985).

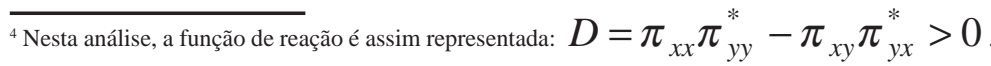


O que pode ser destacado nos dados é a dependência direta da quantidade comercializada, dos preços e dos custos pelas firmas produtoras no próprio país, caso sejam utilizados subsídios pelo governo do país doméstico. No caso da utilização de subsídios pelo país concorrente, verifica-se relação inversa, o que condiz com o já descrito na literatura. Quanto à utilização de imposto de importação, não foi possível definir a relação existente, porém esta análise será feita posteriormente. O que se nota é que o nível ótimo de imposto ou subsídio cobrado pelo país importador tem relação direta com as produções dos dois países exportadores

Nota-se que, para avaliar a condição de mudanças nos preços, é necessário identificar o impacto do subsídio nos preços, ou seja, $p_{s} \equiv \frac{d p}{d s}=p^{\prime}\left(x_{s}+y_{s}\right) ;$ assim, $p_{s}$ passará a ser representado por $p^{\prime}$, assim será considerado para $p_{s^{*}}$ e $p_{t}$.

Ao reforçar a suposição feita inicialmente, de que não há consumo doméstico nos países produtores / exportadores, e considerar, ainda, que as funções de demanda são lineares e os custos marginais são constantes, tem-se, então, que $\pi_{x x}=\pi_{y y}^{*}=2 p^{\prime} ; \pi_{x y}=\pi_{y x}^{*}=p^{\prime}$. Com estes dados, obtém-se:

$$
\begin{aligned}
& x_{t}=y_{t}=\frac{1}{3 p^{\prime}} ; x_{s}=y_{s}{ }^{*}=-\frac{2}{3 p^{\prime}} ; x_{s^{*}}=y_{s}=\frac{1}{3 p^{\prime}} \\
& s=-\frac{x p^{\prime}}{2} ; s^{*}=-\frac{y p^{\prime}}{2} \text { e } t=-\frac{X p^{\prime}}{2}
\end{aligned}
$$

Esses dados revelam a influência das relações entre os volumes produzidos e comercializados (exportados e importados) e os subsídios e, ou, impostos cobrados pelos respectivos governos sobre os preços vigentes no mercado. 
As implicações de variações dos subsídios sobre a receita marginal do país importador, advinda do imposto, dado que $X$ depende de $s$ e $t$, podem ser verificadas por:

$$
\frac{d t}{d s}=\frac{-p^{\prime} X_{s}}{\left(2+p^{\prime} X_{t}\right)} .
$$

Na análise dos impactos de mudanças nos impostos sobre os subsídios, obtém-se:

$$
\frac{d s}{d t}=\frac{-p^{\prime} x_{t}}{\left[2+p^{\prime}\left(x_{s}+x_{s^{*}}\right)\right]} \text {. }
$$

Como pode ser verificado, o subsídio doméstico sofrerá impactos de variações no imposto por meio de variações em sua produção e de variações nos preços vigentes no mercado.

Dessas relações, conclui-se que há dependência direta da utilização de instrumentos de política estratégica de comércio exterior para com a definição dos preços e dos volumes comercializados.

\section{Análises dos impactos das políticas estratégicas de comércio exterior}

Ao admitir $p=a+p^{\prime} X$ e custos constantes $\left(c=c^{\prime}\right)$, podem-se determinar as variações percentuais nas quantidades comercializadas, decorrentes de modificações nos instrumentos de Política Estratégicas de Comércio Exterior, conforme disposto na Tabela 2. 
Pelos dados obtidos, pode-se constatar que a inclusão de subsídio pelo país doméstico resulta em aumento de $20 \%$ no volume comercializado por este país, quando comparado com o caso em que não houver nenhum subsídio. O volume negociado no país importador teria aumento de $10 \%$.

Tabela 2 - Variações percentuais nas quantidades comercializadas quando foram feitas modificações nos instrumentos de Política Estratégicas de Comércio Exterior

\begin{tabular}{lccll}
\hline & $\begin{array}{l}\text { Exportador } \\
\text { Doméstico }\end{array}$ & $\begin{array}{l}\text { Exportador } \\
\text { Estrangeiro }\end{array}$ & $\begin{array}{l}\text { Importador } \\
\text { Estrangeiro }\end{array}$ \\
\hline $\begin{array}{l}\text { Sem Nenhum } \\
\text { Subsídio }\end{array}$ & Sem Imposto & $100,0 \%$ & $100,0 \%$ & $100,0 \%$ \\
\hline $\begin{array}{l}\text { Com Subsídio } \\
\text { Doméstico }\end{array}$ & Sem Imposto & $120,0 \%$ & $100,0 \%$ & $110,0 \%$ \\
\hline $\begin{array}{l}\text { Ambos os Países } \\
\text { Subsidiam }\end{array}$ & Sem Imposto & $120,0 \%$ & $120,0 \%$ & $120,0 \%$ \\
\hline $\begin{array}{l}\text { Sem Nenhum } \\
\text { Subsídio }\end{array}$ & Com Imposto & $75,0 \%$ & $75,0 \%$ & $75,0 \%$ \\
\hline $\begin{array}{l}\text { Com Subsídio } \\
\text { Doméstico }\end{array}$ & Com Imposto & $85,7 \%$ & $75,0 \%$ & $80,4 \%$ \\
\hline $\begin{array}{l}\text { Ambos os Países } \\
\text { Subsidiam }\end{array}$ & Com Imposto & $85,7 \%$ & $85,7 \%$ & $85,7 \%$ \\
\hline
\end{tabular}

Fonte: Cálculos obtidos segundo o modelo de Brander e Spencer (1985).

Caso os dois países exportadores utilizassem subsídios, a elevação no volume comercializado seria de $20 \%$ em cada país, ou seja, no volume total negociado mundialmente.

Caso existissem subsídios dos países produtores e caso fosse cobrado um imposto de importação, a redução no volume comercializado mundialmente seria de $25 \%$, quando comparado com o caso em que não houvesse nenhuma política estratégica de comércio exterior.

Pode-se, verificar, ainda que a inclusão dos subsídios doméstico e estrangeiro na comercialização resultaria na elevação de $30,6 \%$ na receita marginal oriunda da cobrança do imposto. Caso somente um dos países exportadores utilizasse subsídio, a elevação na receita marginal oriunda da cobrança do imposto seria de, aproximadamente, $14,3 \%$. 
Caso os países importadores de determinado produto resolvessem taxar suas importações de países que subsidiavam suas exportações, as receitas oriundas da arrecadação com a importação aumentariam em torno de $14,8 \%$. No entanto, haveria cobrança de impostos no país importador, e os gastos com subsídios dos governos de países exportadores cresceriam $96 \%$.

\section{Considerações finais}

A utilização de instrumentos de política estratégica de comércio exterior afeta o comportamento das firmas no mercado internacional. Por exemplo, a aplicação de subsídios aumenta a quantidade comercializada no país que utiliza esse instrumento, pois reduz o custo final de produção, uma vez que diminui os gastos com comercialização, tornando seus preços mais competitivos no mercado internacional. Essa redução nos custos leva à diminuição nas cotações dos preços no mercado internacional, favorecendo, principalmente, os países importadores.

A utilização de instrumentos de políticas de comércio externo pelos países importadores, considerando a existência de subsídio nos países exportadores, provocaria redução na quantidade comercializada no mercado internacional. Essa redução estaria relacionada com a "exclusão" de parte dos benefícios oriundos dos subsídios dos países produtores, o que poderia ser considerado, inclusive, instrumento de transferência de renda entre os países.

Isto leva a conclusão que há dependência direta da utilização de instrumentos de política estratégica de comércio exterior para com a definição dos preços e dos volumes comercializados.

\section{Referências}

ALVES, Alexandre F.; ARAÚJO, Paulo F. C. de Investimentos na agricultura brasileira: estimações alternativas de 1980 a 1998. Revista 
de Economia e Sociologia Rural, v.40, nº .4, out./dez., Brasília: SOBER, p.755-68. 2002.

ANIS, Aslam H.; ROSS, Thomas W. Imperfect competition and paretoimproving strategic trade policy. Journal of International Economics, 33, p. 363-71. 1992.

BAGWELL, Kyle; STAIGER, Robert W. Strategic trade, competitive industries and agricultural trade disputes. NBER working paper 7822, Cambridge, Mass. Disponível em <http://www.nber.org/papers/w7822> acesso em 10/01/03. 2000.

An economic theory of GATT. NBER working paper 6049, Cambridge, Mass. Disponível em <http://www.nber.org/papers/w6049> acesso em 10/01/03. 1997.

BRANDER, James A. Strategic Trade Policy. In: GROSSMAN, Gene M. \& ROGOFF, Kenneth. Handbook of International Economics, Elsevier. 1995.

; SPENCER, Barbara J. Export subsidies and international market share rivalry. Journal of International Economics, 18, p. 83-100. 1985.

Trade warfare: tariffs and cartels. Journal of International Economics, 16, p. 227-42. 1984.

CARMICHAEL, Calum M. The control of export credit subsidies and its welfare consequences. Journal of International Economics, 23, p. 1-19. 1987.

DE MEZA, David Export subsidies and high productivity: cause or effect? Canadian Journal of Economics, 19, p.347-50. 1986. 
DIXIT, Avinash K.; GROSSMAN, Gene M. Target export promotion with several oligopolistic industries. Journal of International Economics, 21, p. 233-49. 1986.

FIGUEIREDO, Adriano M. R.; FERREIRA, Adriana V.; TEIXEIRA, Erly C. Impactos de uma desvalorização cambial sobre as relações de produção na cultura do café. Revista de Economia e Sociologia Rural, v.37, nº.4, out./dez., Brasília: SOBER, p.47-69. 1999.

GOLDIN, Ian; REZENDE, Gervásio C. de A agricultura brasileira na década de 80: crescimento numa economia em crise. Série IPEA, 138, Rio de Janeiro.1993.

KRISHNA, Kala; THURSBY, Marie C. Optimal policies with strategic distortions. Journal of International Economics, 31, p. 291-308. 1991.

MAS-COLLEL, Andreu; WHINSTON, Michael D.; GREEN, Jerry R. Microeconomic theory. Oxford University Press, New York, 1995.

MAPA. Série histórica da balança comercial brasileira e do agronegócio. Disponível em $<$ http://www.agricultura.gov.br $>$ acesso em 08/02/06. 2006.

MDIC. Evolução do Comércio Exterior Brasileiro - 1950 a 2002. Disponível em < http://www.mdic.gov.br $>$ acesso em 13/02/03. 2003.

PONT-VIEIRA, Maria del C. O sistema GATT e sua importância para o comércio internacional agrícola. IPEA,. Estudos de Política Agrícola. n.28, p.265-304. 1994.

REZENDE, Gervásio C. de Integração de mercados, política de preços mínimos e expansão agrícola da região Centro-Oeste. In: CONGRESSO BRASILEIRO DE ECONOMIA E SOCIOLOGIA RURAL, 39. Recife, 2001. Anais... Recife: SOBER, CD-ROM. 2001.

ROSÁRIO, José B. F. do A evolução da competitividade no 
comércio dos principais produtos "in natura" e processados no Brasil; 1980-1999. Dissertação (Mestrado em Economia Rural), Universidade Federal de Viçosa - UFV/DER, Viçosa, 2001.

TAVARES, Carlos E. C. Estudo para proposta de preço mínimo: safra 2002/03. Companhia Nacional de Abastecimento, CONAB. Disponível em <http://www.conab.gov.br> acesso em 15/02/03. 2003.

TIMMER, C. Peter; FALCON, Walter; PEARSON, Scott. Food policy analysis. The Johns Hopkins.cap.5, 1983.

WTO The World Trade Organization. Disponível em < $\underline{\text { http:// }}$ www.wto.org> acesso em 12/02/03. 2003.

Abstract - International market for some agricultural commodities can be characterized by oligopoly, in which participants behave in a non cooperative manner, provoking marketing disputes. According to this scenario, strategic trade policies have been utilized to as an instrument of market share contents by international market members. Hence, when a country adopts some strategic trade policy, impacts of such policy are felt by other market participants. A subsidy granted by an exporting country, for instance, may result on a raise in exports; whereas taxing production of exports may work as a deterrent to shipments to the international market.

Keywords: strategic trade policy, international market. 